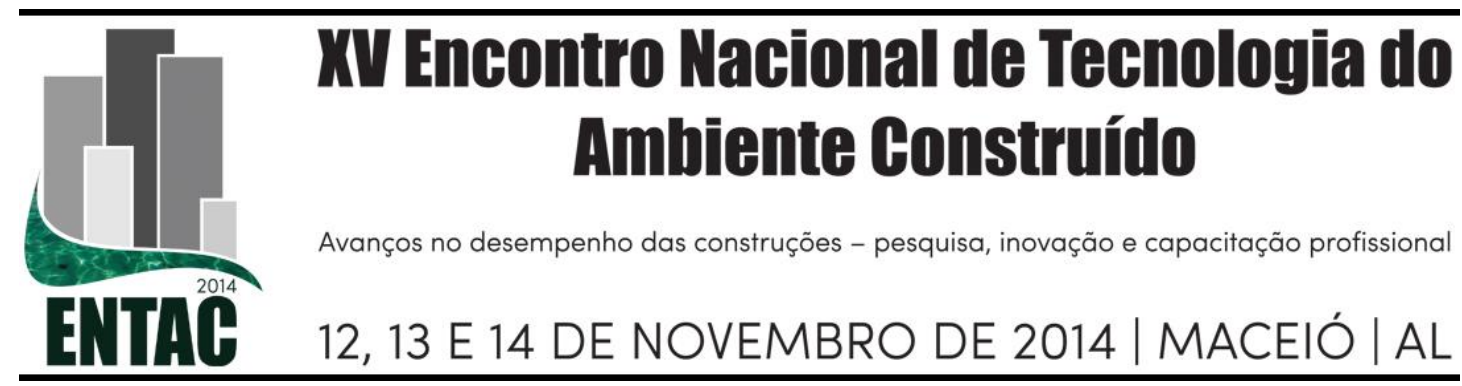

\title{
AVALIAÇÃO DA SATISFAÇÃO PÓS-OCUPAÇÃO DAS UNIDADES HABITACIONAIS DO CONJUNTO HABITACIONAL JULIETA BUENO DO MUNICÍPIO DE CASCAVEL/PR
}

\author{
CASANOVA, Natália Regina (1); MUKAI, Hitomi (2); ZAGO, Emmanuelle \\ Albara (3); SIQUEIRA, Marta Mitiko Kubota de (4)
}

(1)Universidade Estadual do Oeste do Paraná - UNIOESTE, (45) 9981-4449, taia_casanova@hotmail.com (2) Universidade Estadual do Oeste do Paraná - UNIOESTE, hitomi.mukai@hotmail.com, (3) Universidade Estadual do Oeste do Paraná - UNIOESTE, manu_zago@msn.com (4) Universidade Estadual do Oeste do Paraná - UNIOESTE, martamks@gmail.com

\begin{abstract}
RESUMO
A necessidade de produzir conjuntos habitacionais populares com custo reduzido e com boa qualidade é um problema desde os anos 60. O Programa de Extensão CAPA-HIS - Capacitação de entidades de Cascavel-PR para implantação e melhoria de sistemas de gerenciamento de Empreendimentos Habitacionais de Interesse Social, desenvolvido pela UNIOESTE, insere-se nesse esforço. O objetivo do programa é desenvolver parâmetros para unidades habitacionais, obtidos por meio de entrevistas com moradores do Conjunto Habitacional Julieta Bueno, Bairro Interlagos, município de Cascavel/PR. Os resultados apresentados nesse artigo são de análises finais do programa. O método utilizado foi de levantamentos e estudo de caso, com o objetivo exploratório do Conjunto Habitacional Julieta Bueno. No presente artigo estão apresentados os dados sobre a satisfação com a unidade habitacional do Conjunto, em uma amostra não probabilística, das 473 casas do conjunto foram entrevistadas 92, aproximadamente $20 \%$ das unidades. Alguns dos resultados obtidos são de que moradores estão satisfeitos com parâmetros como iluminação e temperatura (60\%), mas quando se trata de acabamentos e cobertura ocorre a insatisfação (40\%), ressalta-se que as casas foram entregues sem reboco e forro, no primeiro caso reflete no visual rústico e no segundo a influência que ocorre nas habitações pela transmissão de temperatura.
\end{abstract}

Palavras-chave: Conjunto Habitacional Julieta Bueno; Satisfação; CAPA-HIS.

\begin{abstract}
The need to produce public housing complex with low cost and good quality is a problem since the 60's. The Program of extension CAPA-HIS - Training of entities from Cascavel-PR for implementation and improvement of management of Social Interest Housing Complex, developed by UNIOESTE, is part of that effort. The program's goal is to develop parameters for housing units, obtained through interviews with residents of the Juliet Bueno's Housing Complex, neighborhood Interlagos, Cascavel/PR. The results presented in this article are the final analysis of the program. The method used was a survey and case study, with the goal of exploratory Juliet Bueno's Housing Complex. In the present article presents data on satisfaction with housing unit set in a non -probabilistic sample, of 473 houses of assembly were 92 respondents, approximately 20\% of the units. Some of the results are that residents are satisfied with parameters such as temperature and lighting (60\%), but when it comes to finishes and coverage occurs dissatisfaction (40\%), it is noteworthy that the houses were delivered without plastering and lining, in first case reflects the rustic look and the second the influence that occurs in the housing for transmitting temperature.
\end{abstract}

Keywords: Juliet Bueno's housing complex; Satisfaction; CAPA-HIS. 


\section{INTRODUÇÃO}

Os estudos sobre habitação de interesse social no Brasil começaram entre as décadas de 50 e 60, tornando-se mais evidente a partir da década de 70, quando as universidades através dos programas de pós-graduação constituíram uma área específica de estudos e pesquisas em ciências sociais, arquitetura, planejamento e construção civil. Segundo Valladares (1983), durante anos a maioria dos estudos concentrava-se na análise da experiência da criação do Banco Nacional de Habitação (BNH).

Para Abiko (1995), a habitação é o espaço ocupado antes e após as jornadas de trabalho, utilizado para as tarefas primárias como alimentação, descanso, atividades fisiológicas e convívio social. Portanto, pode-se entender que a habitação deve atender os princípios básicos de habitabilidade, segurança e salubridade.

A habitação de interesse social tem recebido muita atenção por parte das universidades e governo, pois é um tema de grande importância econômica e social do país (BOLAFFI, 1979). Segundo Maricato (2009), ter conhecimento sobre a produção em relação ao tema é indispensável para que se possam conhecer as situações reais de precariedade habitacional existentes em nosso país, e os desvios nas políticas públicas, que consequentemente se tornam incapazes de sanar a carência das camadas mais pobres da população.

O termo Habitação de Interesse Social (HIS) define várias questões de moradia relacionadas à população de baixa renda, onde tem prevalecido nos estudos voltados para a população com renda entre 0 a 3 salários mínimos. Esse termo também é usado por várias instituições e agências.

\footnotetext{
Atualmente, após a ascensão dos governos de esquerda, as políticas públicas passaram a ser construídas com a participação popular. Os movimentos sociais e a sociedade civil organizada passaram a ter mais espaço de representação junto aos órgãos públicos de decisão. Bons exemplos são os Conselheiros das Cidades e o Conselho Nacional de Habitação de Interesse Social. (ALMEIDA, 2007)
}

Os aspectos sobre o comportamento demográfico brasileiro, juntamente com os indicadores sociais, são necessários para saber a expansão da habitação de interesse social, pois provocam mudanças consideráveis nos requisitos dos usuários de habitações, exigindo flexibilidade, habitabilidade e satisfação dos ambientes construídos (LARCHER, 2014).

No estudo realizado por Leite (2005), envolvendo pesquisa de satisfação com moradores de diferentes empreendimentos, teve o objetivo de identificar oportunidades de melhorias para os clientes deste tipo de empreendimento, entendendo o programa de necessidades como um processo que visa uma melhor compreensão sobre os clientes, melhores definições de projeto e maior agregação de valor ao produto final habitação. Os resultados obtidos apontaram, por um lado, níveis altos de satisfação dos moradores entrevistados, especialmente no que diz respeito a fatores referentes aos condomínios propriamente ditos (segurança, área de lazer, e segurança). Por outro lado, o estudo apontou descontentamento dos entrevistados em relação ao projeto dos apartamentos, em especial no que diz respeito à integração da cozinha com área de serviço, e à falta de espaço para estender roupas.

É importante destacar os aspectos de dimensionamento espacial em relação ao uso adequado dos espaços. Em termos de flexibilidade, dependências com áreas maiores facilitam o arranjo do mobiliário além de possibilitar diferentes usos. Contudo, no caso 
da habitação social no Brasil, alguns aspectos relacionados ao dimensionamento dos cômodos têm sido fortemente desconsiderados em conjuntos habitacionais.

No estudo realizado por Leite (2005) foi identificado que uma das falhas no processo inteiro está no desconhecimento e desconsideração por parte dos construtores e projetistas, dos requisitos dos usuários dos empreendimentos. Os projetistas e construtores entendem que a CAIXA é o seu cliente, uma vez que se trata do agente financiador. Com isso, não possuem contato com o morador e usuário final do produto que produzem.

Verifica-se a existência de diversos estudos sobre o projeto da habitação de interesse social, embora com pouco esforço quanto ao impacto das decisões arquitetônicas no uso e no custo final destes empreendimentos, assim como há pouca discussão sobre alternativas para melhores condições de habitabilidade garantindo a satisfação dos moradores. Neste contexto, o presente trabalho apresenta os resultados obtidos sobre satisfação com a unidade habitacional, através de entrevistas realizadas com moradores do Conjunto Habitacional Julieta Bueno, do município de Cascavel/Pr.

O Conjunto em questão foi construído para retirar moradores do Loteamento Gramado e de ocupações ilegais em Fundos de Vale onde viviam em péssimas condições de habitabilidade, muitos inclusive moravam em barracos de lona. Foi inaugurado em maio de 2002. Na primeira fase de implantação das famílias, além de 473 unidades habitacionais, o conjunto recebeu infraestrutura, e uma área destinada à implantação do NAF - Núcleo de Apoio às Famílias. O pagamento da moradia está dividido em 240 parcelas, sendo o valor inicial de $\mathrm{R} \$ 30,00$, o qual é reajustado anualmente, conforme o índice da poupança.

\section{OBJETIVO}

Analisar qualitativa e quantitativamente a satisfação pós-ocupação nas unidades habitacionais do Conjunto Habitacional Julieta Bueno do município de Cascavel/PR.

\section{JUSTIFICATIVA}

O tema habitação de interesse social vem sendo objeto de diversos estudos e pesquisas. Levando em conta que o estudo da habitação não deve focar apenas na distribuição das residências, mas também na adaptação social e econômica das famílias beneficiárias à nova moradia.

Nesse contexto, torna-se necessário um estudo atento às condições de pósocupação das unidades habitacionais, focando na satisfação dos usuários e sua percepção das condições de moradia.

O presente estudo questiona diretamente aos moradores das unidades habitacionais do Conjunto Habitacional Julieta Bueno do município de Cascavel/PR sobre as condições das residências recebidas e a sua qualidade de vida. Assim, através de entrevistas, tem-se um diagnóstico, feito pelos próprios beneficiários, que retrata o impacto das decisões arquitetônicas na qualidade e custo de uso da moradia.

Através dos resultados obtidos pode-se reavaliar o processo construtivo e as reais necessidades dos futuros moradores das unidades habitacionais, de maneira e executar residências com um projeto arquitetônico cada vez mais otimizado, que melhore a qualidade da moradia. 


\section{MÉTODO EMPREGADO}

A metodologia empregada para esse artigo foi de survey, através de questionários com os moradores do conjunto habitacional. Nesses questionários exploraram-se vários temas: Caracterização socioeconômica; Caracterização de modificações internas ou ampliações nas casas; Caracterização de modificações nos acabamentos das casas; Caracterização de modificações internas; Satisfação com a Unidade Habitacional; Patologias. A pesquisa foi aplicada no Conjunto Habitacional Julieta Bueno, localizado no Bairro Interlagos, no município de Cascavel.

Nesse artigo, focamos somente no quesito Satisfação com a Unidade Habitacional. Foram aplicados 96 questionários, 20\% do total de casas do conjunto.

\section{RESULTADOS OBTIDOS}

Os resultados apresentados aqui se referem a análises finais do Programa de Extensão CAPA-HIS. Dentro do tema "satisfação com a unidade habitacional" trabalharam-se os seguintes assuntos: adequação do espaço ao mobiliário e às atividades programadas; condições naturais de conforto; instalações elétricas; instalações hidrossanitárias; qualidade dos acabamentos; janelas e portas. Com os itens trabalhados geraram-se gráficos de satisfação e insatisfação, que serão apresentados a seguir.

Deve-se lembrar de que o conjunto já tem quase 12 anos e que muitas unidades habitacionais já foram modificadas e ampliadas, fato que altera significativamente nos resultados de satisfação. Essas modificações, na maioria, se referem à troca de aberturas e pintura da casa, o que elevam os níveis de satisfação dos moradores. Para melhor explicar, as figuras abaixo apresentam a planta baixa original das casas do conjunto e um exemplo de planta baixa de casa modificada, respectivamente. Das 96 casas visitadas, $73 \%$ apresentaram modificações.

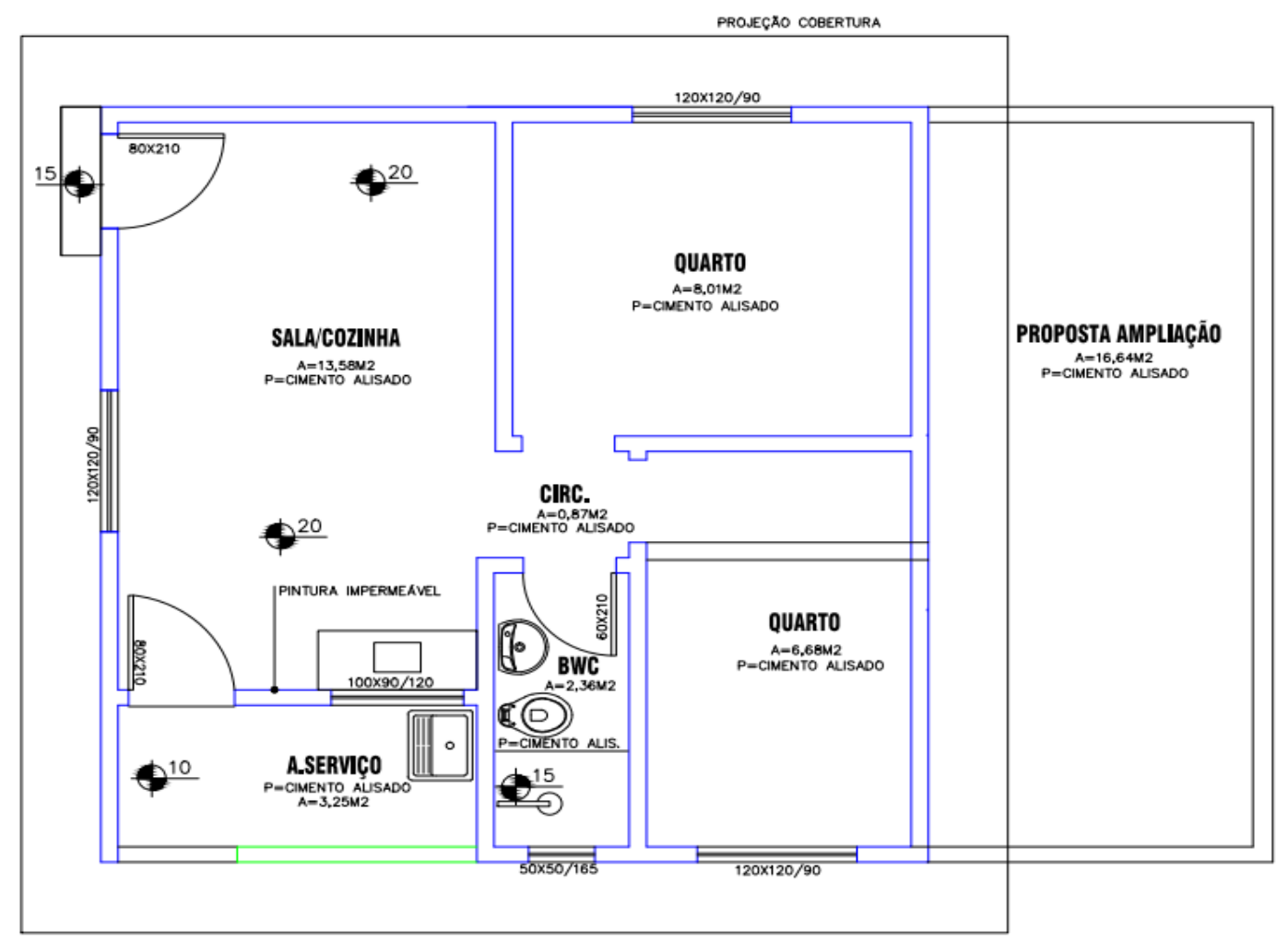

ÁREA TOTAL $=40,00 \mathrm{M} 2$

Figura 1: Planta baixa original do Conjunto Julieta Bueno (sem escala) 


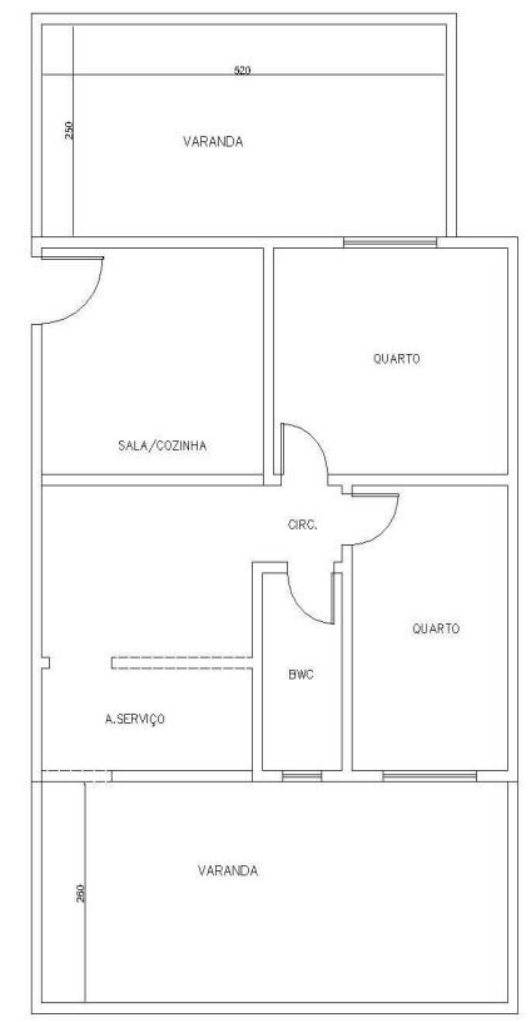

Figura 2: Planta baixa modificada do Conjunto Julieta Bueno (sem medidas e escala)

\subsection{Adequação do espaço ao mobiliário e às atividades programadas}

Este quesito tem relação ao espaço existente com o mobiliário que está na unidade habitacional, se há lugar para os móveis existentes e ainda para passagem de pessoas. Foi perguntado sobre a área de estar e jantar, cozinha, área de serviço, dormitórios e banheiro. A maioria dos entrevistados gostariam que o banheiro fosse maior ( $47 \%$ insatisfação) e que a área de serviço fosse coberta (45\% insatisfação).

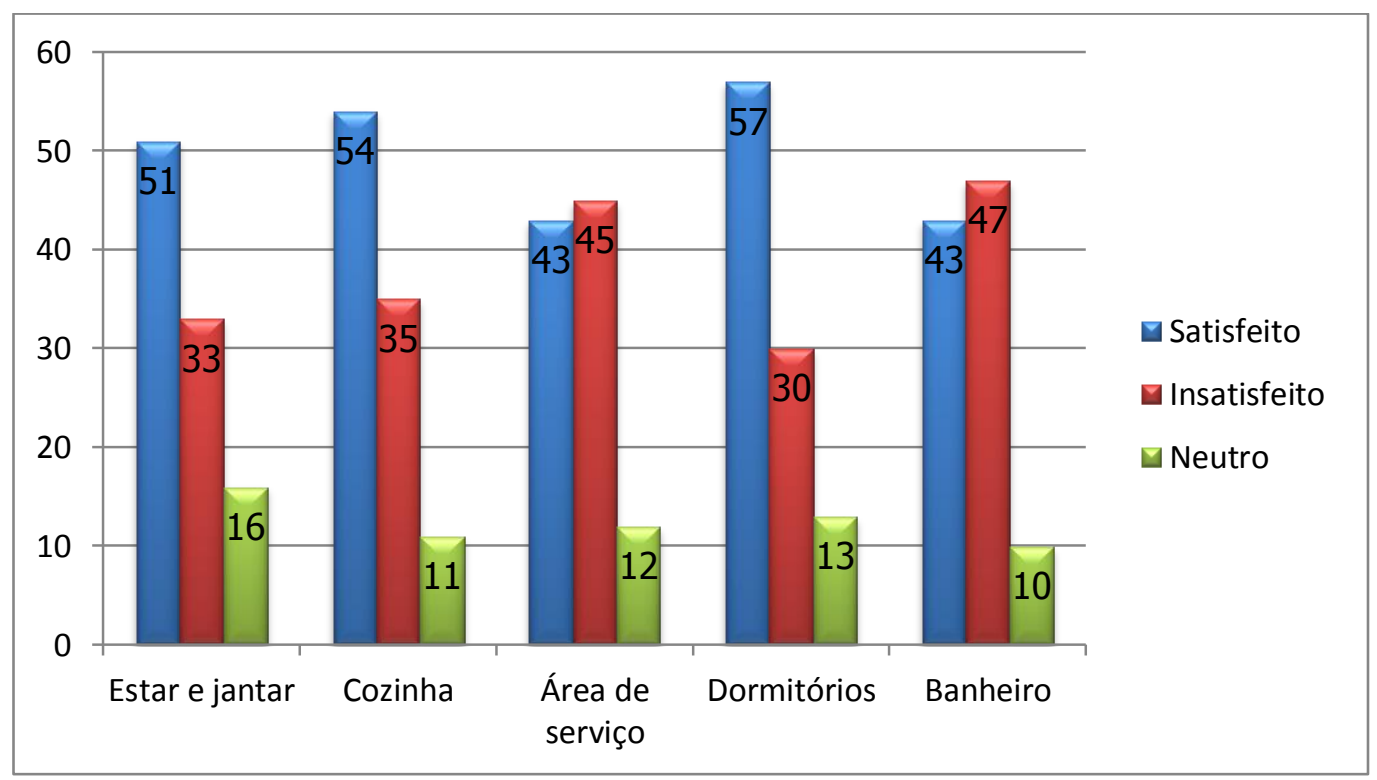

Gráfico 1: Adequação do espaço ao mobiliário e às atividades programadas 


\subsection{Condições naturais de conforto}

Neste ponto, perguntava-se sobre a temperatura interna no inverno e verão, iluminação natural dos ambientes e níveis de ruído de fora para dentro da casa. Como as unidades são relativamente pequenas, não foi questionado por peça da unidade, e sim de um modo geral. Vale lembrar que na cidade de Cascavel o inverno e verão são muito intensos.

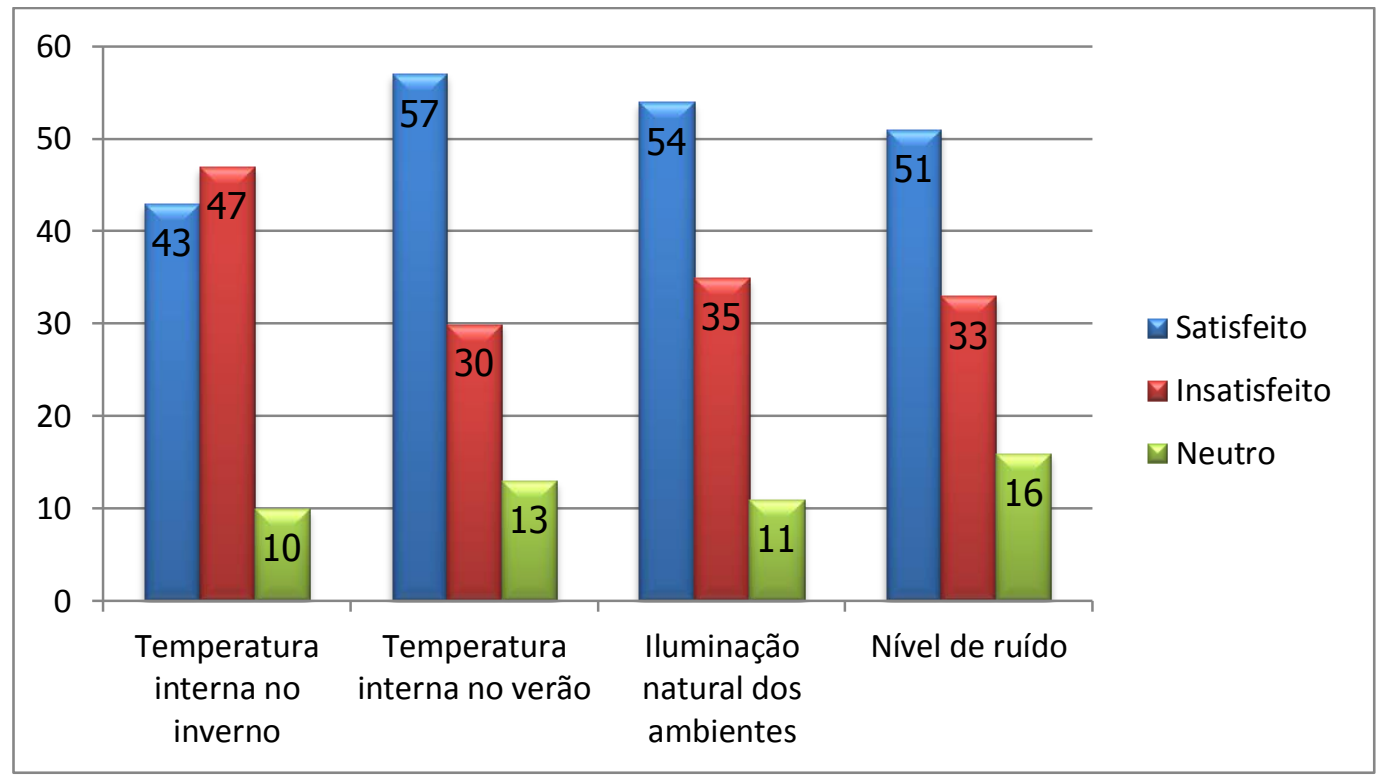

Gráfico 2: Condições naturais de conforto

\subsection{Instalações elétricas}

No que se refere às instalações elétricas, questionou-se sobre o funcionamento das instalações, quantidade de pontos elétricos e localização dos pontos elétricos. Nesse quesito não houve muita insatisfação, lembrando-se do detalhe que a maioria das casas já foram reformadas. As modificações nesse caso foram no funcionamento, fazendo a troca de lâmpadas e tomadas (nenhuma casa declarou ter instalado mais pontos elétricos).

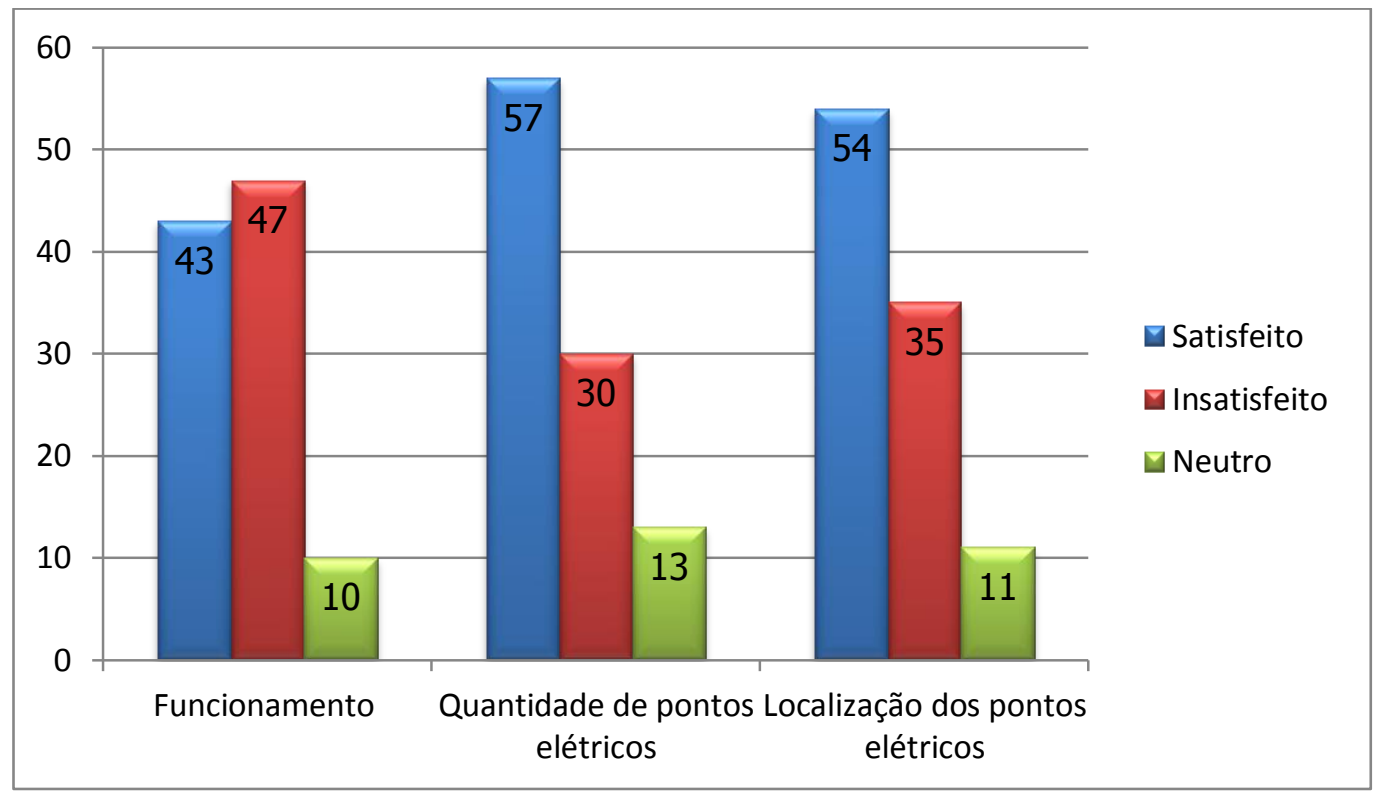

Gráfico 3: Instalações elétricas 


\subsection{Instalações hidrossanitárias}

Sobre instalações hidrossanitárias, perguntou-se a respeito do funcionamento, quantidade de pontos de água e esgoto, localização dos pontos de água e esgoto, qualidade dos metais sanitários (torneiras, registros) e qualidade das louças sanitárias (vaso, lavatório). A satisfação dos usuários em relação a esse ponto é muito alta devido as modificações existentes nas casas, mas nas casas em que não haviam mudado nada, os moradores reclamavam principalmente da qualidade do produto que havia sido empregado. Aqui, as modificações são nas torneiras e vaso sanitário, $75 \%$ das casas questionadas fizeram a troca desses materiais, pois o material que foi entregue junto com a casa era de baixa qualidade.

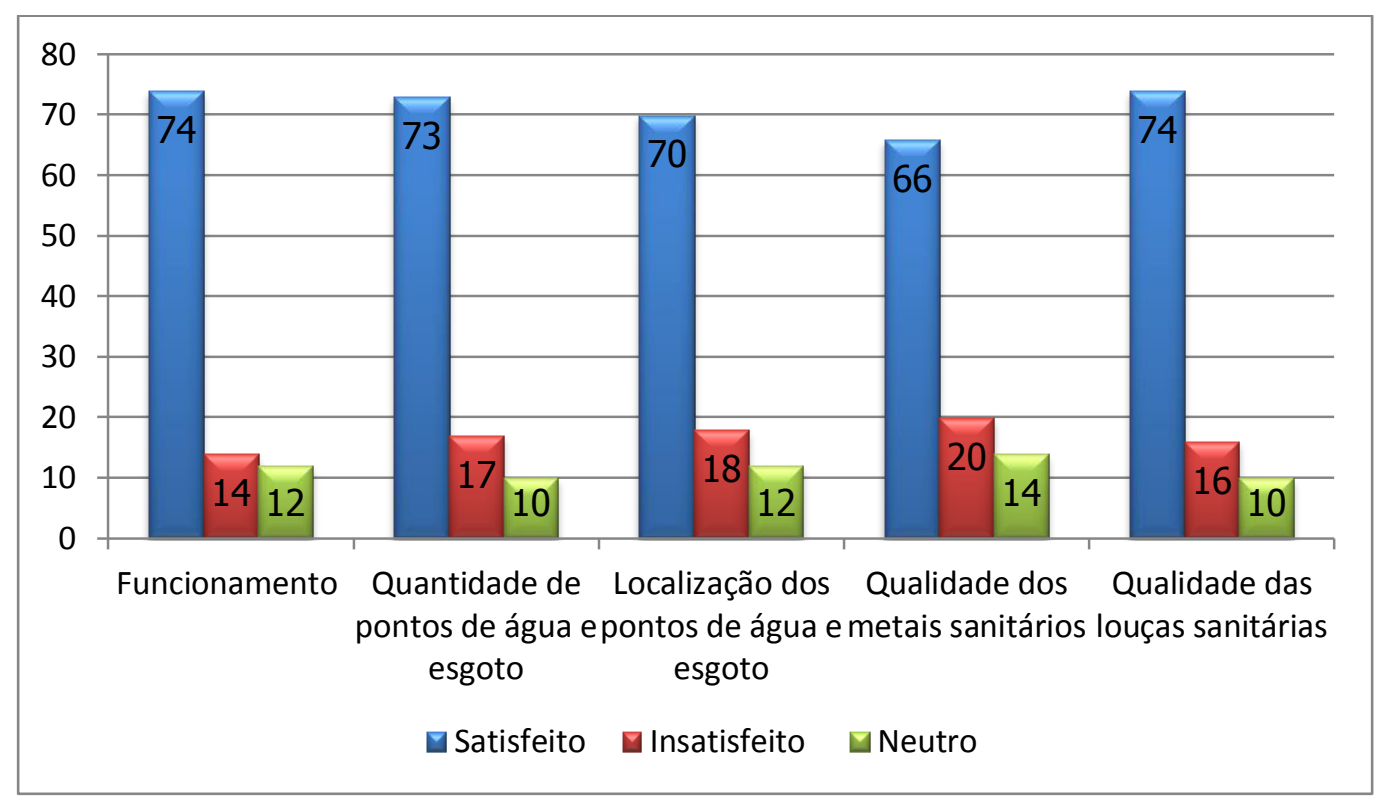

Gráfico 4: Instalações hidrossanitárias

\subsection{Qualidade dos acabamentos}

Sobre a qualidade dos acabamentos na casa, a satisfação ainda está evidente devido às reformas, mas como as casas foram entregues sem forro e algumas até sem pintura, a insatisfação não se distancia muito. Aqui se questionou sobre a qualidade dos pisos, tetos e paredes de toda unidade habitacional. Nesse quesito ficou muito claro que as reformas feitas pelos proprietários aumentaram significativamente o nível de satisfação dos moradores, pois aqueles que ainda possuem a casa em sua forma original, do jeito que foi entregue, se declararam insatisfeitas com os acabamentos e as que já modificaram estão satisfeitas com a unidade. A principal modificação feita foi a pintura de paredes internas e externas, seguida da colocação de piso interno. 


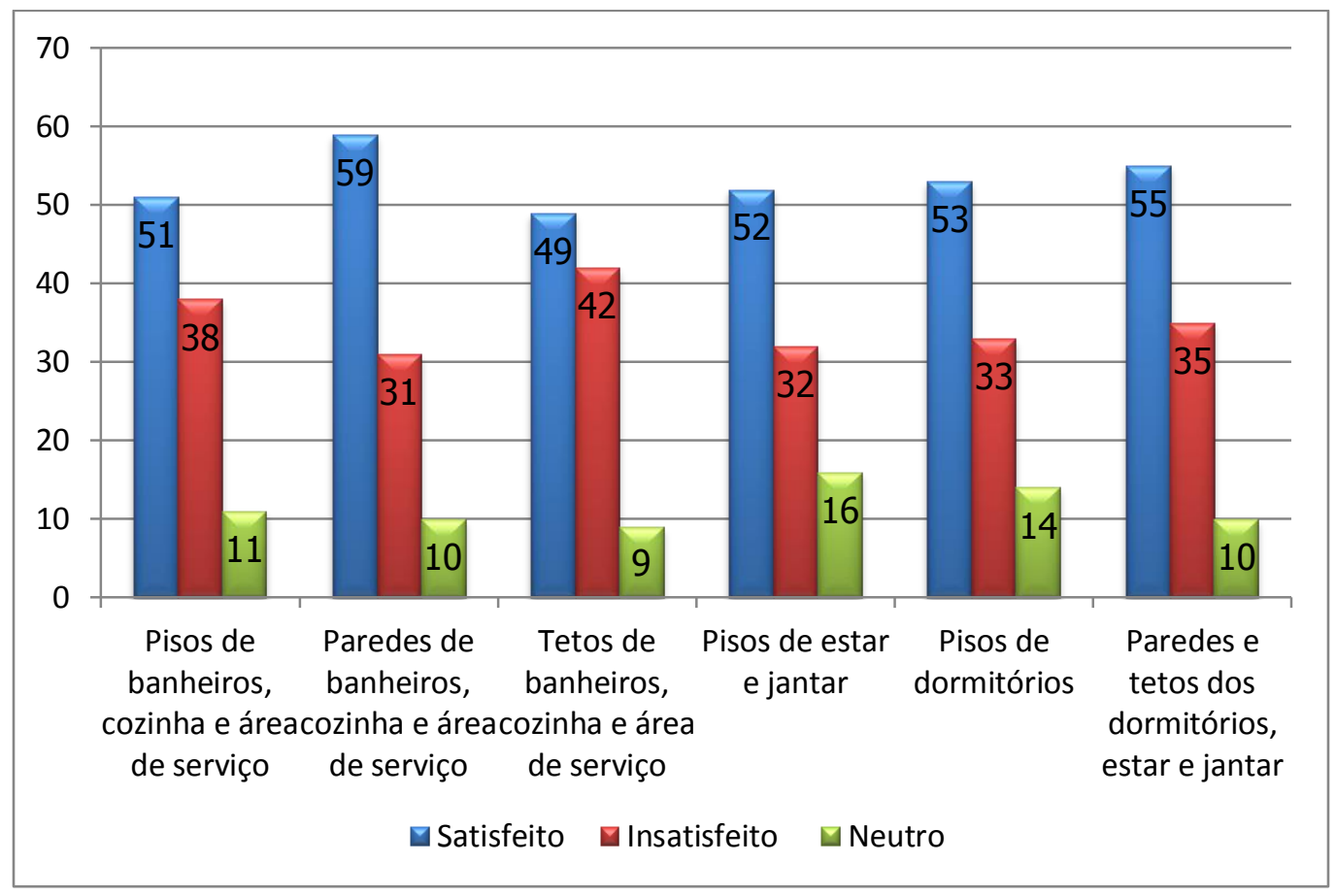

Gráfico 5: Qualidade dos acabamentos

\subsection{Janelas}

No ponto sobre as janelas se perguntou sobre o material empregado (janelas de alumínio), funcionamento das mesmas e qualidade das fechaduras. Como a maioria já trocou, há satisfação. Dos 96 respondentes, 49 haviam feito a troca das janelas.

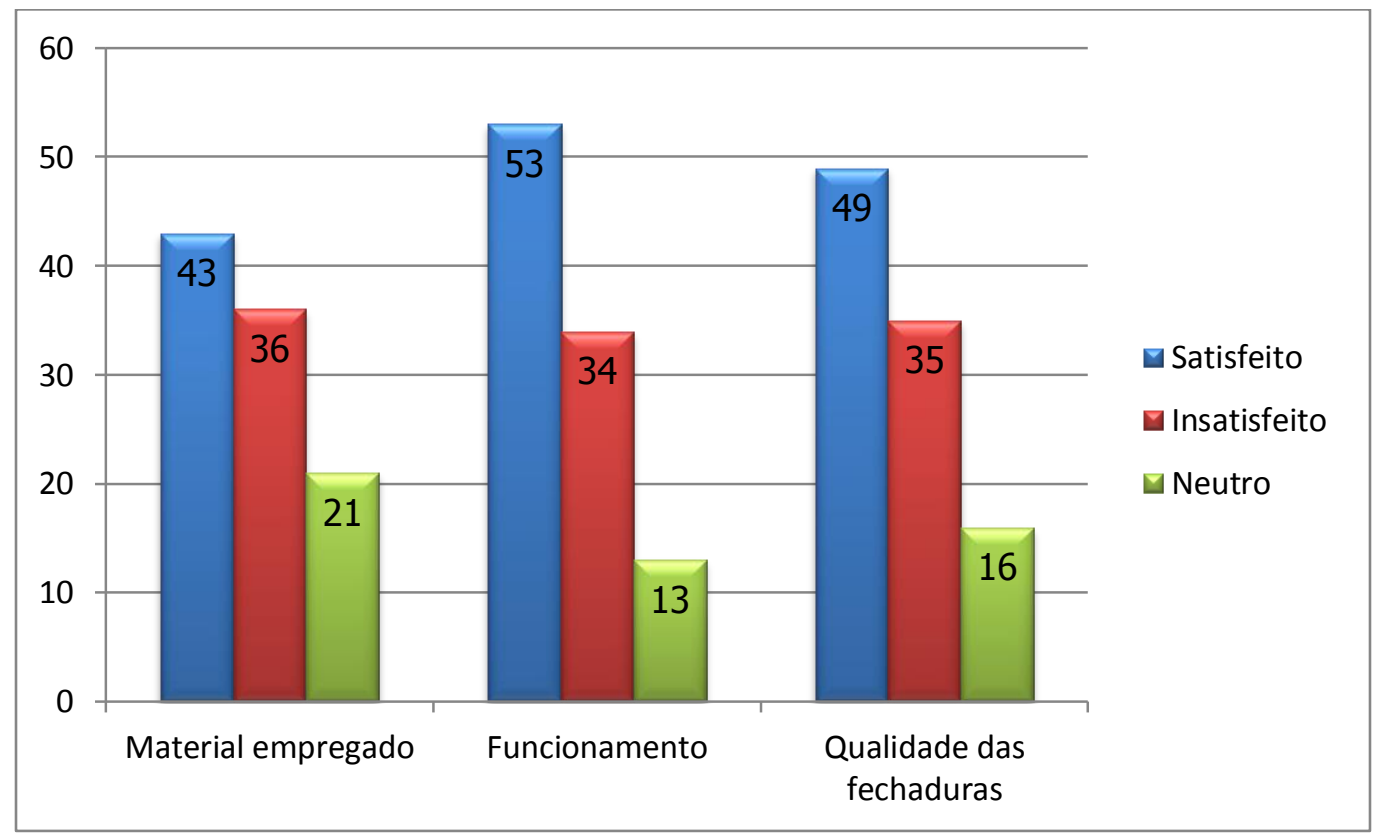

Gráfico 6: Janelas

\subsection{Portas}

Aqui se perguntou os mesmos pontos em relação às janelas. Porém como a porta de alumínio ainda está em grande parte das casas, pode-se notar a pequena diferença 
entre satisfação e insatisfação. Dos 96 respondentes, 51 já haviam feito a troca das portas.



Gráfico 7: Portas

\section{CONSIDERAÇÕES FINAIS}

Todo autor que aborda o tema habitação de interesse social tem a intenção, mesmo mínima, de contribuir com a evolução do tema. Cada pesquisa realizada representa um pouco da realidade do país e da produção acadêmica, com o intuito de contribuir com o tema que envolve a habitação de interesse social no Brasil. Uma das dificuldades para o desenvolvimento da pesquisa foi encontrar publicações com abordagem similar ao desta pesquisa, ou seja, estudos sobre satisfação com as unidades habitacionais dentro da habitação de interesse social no país.

A análise dos dados referentes ao Conjunto Habitacional Julieta Bueno permitiu a identificação de diversas oportunidades de melhoria do espaço construído, levando melhores condições de vivência para as famílias e melhores acomodações.

Por fim, estudar e refletir sobre habitação de interesse social não significa expor fraqueza e fracassos, mas apontar importantes avanços e, num desafio, ter elementos para construir novos rumos. A intenção é desenvolver parâmetros para unidades habitacionais que possam melhorar a habitabilidade da unidade.

\section{REFERÊNCIAS BIBLIIOGRÁFICAS}

ABIKO, A. K. Introdução à gestão habitacional. São Paulo, EPUSP, 1995. Texto técnico da Escola Politécnica da USP, Departamento de Engenharia de Construção Civil, TT/PCC/12. Disponível em:

< http://publicacoes.pcc.usp.br/PDF/ttcap12.pdf > Acesso em 14 mar. 2014.

ABREU, M.G. de. Habitação de Interesse Social no Brasil: Caracterização da produção acadêmica dos programas de pós-graduação de 2006 a 2010. 2012, 156p. Dissertação (mestrado 
em engenharia de edificações e ambiental). Programa de Pós-Graduação em Engenharia de Edificações e Ambiental da universidade Federal de Mato Grosso. Cuiabá-MT. Disponível em: < http://200.129.241.80/ppgeea/sistema/dissertacoes/23.pdf> Acesso em 26 mar. 2014.

ALMEIDA, A. J. de. A participação de assessoria técnica-política e da CAIXA na produção de moradias em assentamentos rurais. Casos: Fusquinha, Nova Esperança e Pirituba 2. Dissertação (Mestrado) -USP, São Carlos, SP, 2007. Disponível em:

<http://www.bdtd.ufscar.br/htdocs/tedeSimplificado//tde_busca/arquivo.php?codArquivo=1995

$>$ Acesso em 10 mar. 2014

BOLAFFI, G. Habitação e urbanismo: o problema e o falso problema, In: MARICATO, E. (org.). A produção capitalista da casa (e da cidade) no Brasil industrial. São Paulo: Editora Alfa - Omega, 1979.

LARCHER, J.V.M. Diretrizes visando a melhoria de projetos e soluções construtivas na expansão de habitações de interesse social. 2005, 189p. Dissertação (mestrado em construção civil). Programa de pós-graduação em construção civil do setor de tecnologia da Universidade federal do Paraná, Curitiba. Disponível em:

< http://www.prppg.ufpr.br/ppgcc/sites/www.prppg.ufpr.br.ppgcc/files/dissertacoes/d0068.pdf> Acesso em 09 mar. 2014.

LEITE, F. L. Contribuições para o gerenciamento de requisitos do cliente em empreendimentos do Programa de Arrendamento Residencial. Dissertação (Mestrado em Engenharia Civil) Escola de Engenharia. Universidade Federal do Rio Grande do Sul: Porto Alegre, 2005. Disponível em: $<$ http://www.lume.ufrgs.br/bitstream/handle/10183/6297/000483805.pdf?sequence=1 $>$ Acesso em 25 mar. 2014.

MARICATO, E. Por um novo enfoque teórico na pesquisa sobre habitação. Cadernos Metrópole. n. 21, $1^{\circ}$ sem. 2009. pp. 33-52. Disponível em:

<http://revistas.pucsp.br/index.php/metropole/article/viewFile/5954/4308> Acesso em 13 mar. 2014.

VALLADARES, L. P. Estudos Recentes sobre habitação no Brasil: Resenha da literatura. In: VALLADARES, L. P.(org). Repensando a habitação no Brasil. Rio de Janeiro: Zahar, 1983. 